\title{
POTENCIALIDADE DO PLANEJAMENTO PARTICIPATIVO NO BRASIL
}

\section{Potentiality of Participative Planning in Brazil}

Ideni Terezinha Antonello

Profa. Associada dos Cursos de Graduação e Pós-graduação de Geografia Universidade Estadual de Londrina antonello@uel.br

Artigo recebido em 15/11/2012 e aceito para publicação em 28/04/2013

Resumo: $\quad$ o objetivo central deste trabalho é realizar uma reflexão das potencialidades apresentadas pelos atuais planos diretores municipais no Brasil em contraposição aos planos tradicionais, pois o Estatuto da Cidade (2001) trouxe uma ressignificação a esses planos ao designá-los de "planos diretores participativos", na orientação de formulação de planos com a perspectiva de uma efetiva participação popular. Para atingir este objetivo será trabalhada a experiência concreta de dois objetos de estudo: o Plano Diretor Participativo e o Orçamento Participativo e tomar-se-á o município de Londrina/ Paraná, para verificar a aplicação dos pressupostos da participação popular na produção do plano diretor municipal e como exemplo da aplicação do orçamento participativo o município de Porto Alegre / Rio Grande do Sul.

Palavras-chave: Planejamento Urbano, Plano Diretor Municipal, Participação Popular.

Abstract: The main objective in this essay is making a reflection upon the potentialities presented by the recent municipal master plans in Brazil compared to the traditional plans, because the City Statute (2001) brought a new meaning to these plans when designating them "participative master plans", in the orientation of formulation of plans on the perspective of an effective popular participation. In order to reach this goal, the concrete experience of two study objects will be developed: the Participative Master Plan and the Participative Budget. The city of Londrina/Paraná will be taken to check the application of the assumptions of popular participation on the production of the municipal master plan, and the city of Porto Alegre/Rio Grande do Sul, as an example of the participative budget application.

Key-words:Urban Planning, Municipal Master Plan, Popular Participation. 


\section{INTRODUÇÃO}

Para adentrar na discussão da potencialidade que se acredita apresentar os atuais planos diretores municipais, é necessário realizar uma contextualização da trajetória histórica do plano diretor municipal no Brasil, na perspectiva de apreender a ressignificação que eles obtiveram com a instituição do Estatuto da Cidade (2001). Para tanto, destaca-se a década de 1980, que, no Brasil, é considerada um marco no desencadear de movimentos sociais, esses, tendo como foco de luta, a política urbana, pois se constituiu no processo de redemocratização no País. Dentre eles, sobressaiu-se o Movimento Nacional pela Reforma Urbana-MNRU.

Cabe salientar o elo existente entre esse movimento e a reforma urbana, elaborada no governo de João Goulart (1961-1964), entendida como uma reforma de base ao lado da propagada reforma agrária. $\mathrm{O}$ fato de a reforma agrária se encontrar em evidência nas décadas de 1950-60 estava relacionado com a presença atuante dos movimentos sociais no espaço rural nacional, particularmente, com a organização e a atuação do movimento Ligas Camponesas (Movimento social que surgiu em Pernambuco, na década de 1950, e se disseminou pelo Brasil em defesa da reforma agrária como a máxima "reforma agrária, na lei ou na marra").

A preocupação do governo Goulart com a construção de propostas políticas e econômicas, voltadas para reformas de base, entre outros fatores nacionais e internacionais, não contribuiu para sua manutenção no poder. Nesse contexto, este governo sofre o Golpe Militar, em 1964, que passa a instaurar o Estado autoritário - Ditadura Militar. Sob o poder autoritário, a discussão em torno de reformas de base entra em letargia, já que os debates críticos que se iniciaram na década de 1960 foram abafados.

Não obstante o germe de uma reforma urbana e não o discurso de uma "reforma urbanística", essa reforma começou a adquirir as condições necessárias para germinar, na década de 1980, com o processo de abertura do Estado autoritário. Nesse ponto, encontra-se o elo entre os dois momentos, ou seja, os princípios da reforma urbana (1960), pensados e debatidos no contexto das reformas de base, e a proposta de reforma urbana, inserida no movimento de redemocratização nacional, já que em ambos os momentos estavam presentes às demandas sociais como a luta por moradia digna, educação, saúde, criação de infraestrutura (saneamento, transporte público entre outros) e contra a especulação dos imóveis urbanos, em síntese, contra as desigualdades socioespaciais que se acentuavam com o processo de urbanização acelerado e desorganizado no Brasil. Tal fato ganhou sentido ao se constatar a seguinte estatística: em 1960, 45,10\% da população nacional encontrava-se no espaço urbano; em 1980, passa para $67,59 \%$; em 1996, para 78,36\%; em 2000, para $81,25 \%$, atingindo a proporção de $84,35 \%$ em 2010 (IBGE, 2000, 2010).

Vale frisar que os movimentos sociais de luta por melhores condições de vida nas cidades desempenharam papel essencial no processo de redemocratização nacional, uma vez que, ao lutarem pelo direito de ser cidadão em relação às condições materiais de existência, fomentaram o questionamento do poder autoritário do Estado comandado pela ditadura militar.

O movimento começava a ganhar seiva com a articulação de forças de outros atores sociais (profissionais liberais, intelectuais, estudantes entre outros). Segundo Cymbalista (2006, p.30) “A conjunção desses atores potencializou a discussão de novos temas, como a politização do debate sobre a legalidade urbanística e a necessidade de abertura da gestão urbana para novos atores sociais".

A união de forças proporcionou uma base de luta sólida na busca de um novo marco para a política urbana. Tal luta refletiu-se na abertura para a participação popular no processo constituinte nacional de 1988, mediante as emendas populares. Essas emendas constituíam-se em propostas de leis feitas pela sociedade civil. Contudo, para a apreciação dessas propostas pela Assembleia Constituinte, era necessário contar com trinta mil assinaturas de eleitores, além do apoio de três entidades. Dessa forma, o Movimento Nacional pela Reforma Urbana (MNRU) obteve cerca de 160.000 assinaturas para encaminhar a Emenda Popular pela Reforma Urbana à Assembleia Constituinte.

Todavia, um detalhe importante assume essência - o Congresso Constituinte - que tinha a obrigatoriedade de receber a proposta de emenda, o que não subentendia que ela seria incorporada na íntegra. 
Por conseguinte, a emenda original passou pelo crivo dos congressistas, logrando a eliminação de vários pontos, como por exemplo, aqueles vinculados aos transportes coletivos, serviços públicos e à aplicação do instrumento da usucapião em terrenos públicos (SOUZA, 2006). Logo, o que ficou da Emenda Popular da Reforma Urbana encontra-se nos artigos 182 e 183 da Constituição de 1988. Destaca-se o artigo 182, a seguir:

A politica de desenvolvimento urbano, executada pelo Poder Público Municipal, conforme diretrizes gerais fixadas em lei, tem por objetivo ordenar o pleno desenvolvimento das funções da cidade e garantir o bem-estar dos seus habitantes. (BRASIL, 1988).

É importante enfatizar esse artigo da política urbana, pois ele elucida a transferência do poder federal para o poder local municipal. Para a aplicação da lei, particularmente, delega aos planos diretores municipais o objetivo de "ordenar o pleno desenvolvimento das funções da cidade e garantir o bem-estar dos seus habitantes" (BRASIL, 1988). No entanto, ressalva-se que, neste artigo, os planos diretores são exigidos somente para as cidades com mais de vinte mil habitantes.

Percebe-se que os planos diretores municipais tornam-se o pressuposto da política de desenvolvimento urbano, evidenciando que, do conflito entre os defensores da emenda popular e os que visavam a uma proposta de reforma urbana mais conservadora, resultou em acordo tático entre os congressistas e os tecnocratas vinculados ao Estado, uma vez que o plano diretor implica transferir, ou melhor, manter a política urbana sob responsabilidade técnica do planejamento urbano.

Essa estratégia para Rolnik (1994, p.357, apud CARVALHO, 2009, p. 49) constituiu-se em "[...] uma espécie de inclusão formal das demandas populares na lógica do regime urbanístico em vigor, reforçando o papel do Estado e imaginando uma cidade conduzida por planos diretores competentes", ou seja, a direção da política urbana não sofreria alteração na sua natureza idealística e tecnicista representada pelo plano diretor tradicional o qual posteriormente será foco dessa análise.
Nesse sentido, nota-se que, no texto constitucional, o plano diretor tornou-se o sustentáculo do regime da propriedade privada, pois a preocupação central dos setores conservadores, vinculados à dinâmica da produção do espaço urbano, era inibir a aplicação dos instrumentos jurídico-urbanísticos previstos no $\S 4^{\circ}$ como, por exemplo, o imposto sobre a propriedade predial e territorial urbana progressivo no tempo e a usucapião especial urbana, uma vez que esses instrumentos possibilitam a concretização da função social da propriedade.

A despeito de a reforma urbana ter ficado enquadrada em dois artigos do texto constitucional, demonstrando o poder de pressão dos grupos dominantes, pode-se considerar que a política de desenvolvimento urbano ganhou a potencialidade de trabalhar com a escala local que proporciona atuação direta dos atores sociais de planejar e gerir o espaço vivido em parceria com o poder local.

Todavia, não se pode perder de vista as forças políticas locais, pois, como alertam Souza e Rodrigues (2004, p. 67), “[...] é indispensável uma regulação mais densa em escala nacional (feita pelo governo federal), para evitar que forças políticas locais conservadoras simplesmente ignorem o texto constitucional ou se aproveitem do seu caráter vago".

Diante da necessidade de uma legislação mais forte em escala federal, é que se pautaram os debates e a atuação dos movimentos sociais que continuaram em ação para instituir uma política urbana consistente. Desse modo, em 1990, foi elaborado o Projeto de Lei 5.788/90, que tramitou até 2001 no Congresso, resultando na Lei $\mathrm{n}^{\circ}$. 10.257 , de 10 de julho de 2001, denominada Estatuto da Cidade. Destarte, o Estatuto é fruto da participação da sociedade. Como salienta Soares:

[...] o Estatuto da Cidade pode ser entendido
como uma Utopia de Processo Social, pois
é o resultado de um longo processo de lutas
e negociações, de pressões da sociedade
civil organizada e dos movimentos sociais
e que condensa e sintetiza uma diversidade
de idéias, ideologias e projetos coletivos de
sociedade. (2003, p. 3 e 4, grifo do autor, apud
RODRIGUES, 2005, p.94).

[...] o Estatuto da Cidade pode ser entendido como uma Utopia de Processo Social, pois é o resultado de um longo processo de lutas e negociações, de pressões da sociedade civil organizada e dos movimentos sociais e que condensa e sintetiza uma diversidade de idéias, ideologias e projetos coletivos de sociedade. (2003, p. 3 e 4, grifo do autor, apud RODRIGUES, 2005, p.94). 
Apesar de o Estatuto da Cidade ter um caráter "utópico", conforme o autor, porquanto apresenta como intuito máximo o direito a uma "cidade ideal", não se pode esquecer a "utopia experimental" de que fala Lefebvre (1991), ou seja, uma utopia que suplante a sua essência de miragem para entrar no movimento da realidade e, assim, assuma uma perspectiva de possibilidade de mudança em face das desigualdades socioespaciais. Como alude Rodrigues (2005, p. 94),

\section{[...] se a Utopia é a exploração de novas} possibilidades, se apenas algumas das idéias utópicas podem ser realizadas, se o que é importante na Utopia é a virtualidade que a torna possivel, então podemos considerar que o Estatuto tem virtualidades para a conquista do Direto à cidade no âmbito do uso do urbano, não extrapolável para outras dimensões da vida urbana.

Sabe-se que uma lei não tem o poder de concretizar a utopia coletiva de uma "cidade ideal", principalmente, no marco de uma sociedade heterônoma. No entanto, pondera-se que o Estatuto constitui-se em um avanço na trajetória do desenho de planejamento e gestão participativos do espaço urbano, ao instituir as diretrizes e os instrumentos com vistas a atingir o objetivo da função social da cidade e da propriedade urbana. O Estatuto proporciona o respaldo jurídico para planejamento e gestão democráticos das cidades e, neste último ponto, destaca-se o Plano Diretor Participativo e o Orçamento Participativo.

Pode-se trabalhar na expectativa de que os planos diretores participativos possibilitem a cristalização do planejamento e gestão das cidades que envolvam a participação da sociedade, mediante a prática de um "planejamento com diálogo" (BUSTELO, 1982) com os atores sociais que produzem e vivem os espaços urbanos. O caminho para atingir esse planejamento está materializado nas possibilidades criadas pelo Estatuto da Cidade a serem exploradas em seu limite para potencializar a aplicação efetiva de seus instrumentos. Tal fato precisa, para sua concretização, da solidez e da força advindas da participação popular.

Dessa contextualização da trajetória histórica do delineamento da origem dos planos diretores par- ticipativos, tem-se como objetivo central deste artigo refletir sobre as potencialidades dos instrumentos presentes no Estatuto da Cidade quanto ao planejamento e à gestão democráticos das cidades, principalmente, o Plano Diretor Participativo e o Orçamento Participativo.

Para atingir este intuito, será trabalhada a experiência concreta desses dois objetos de estudo, (1) o município de Londrina/PR, em relação ao desenvolvimento do plano diretor municipal, para verificar a aplicação dos pressupostos da participação popular na produção do plano diretor municipal; e (2) a aplicação do orçamento participativo o município de Porto Alegre/RS.

Para adentrar na discussão das potencialidades dos "novos" planos diretores, é necessário breve retrospectiva das bases doutrinárias dos "tradicionais" planos diretores para verificar e elucidar o marco de mudanças presente no planejamento e na gestão urbanos na contemporaneidade no Brasil, pois se pondera que uma visão das balizas teóricas dos tradicionais planos diretores pode proporcionar mais clareza para trabalhar com uma perspectiva de planejamento cujo principal foco é o social.

Nesse sentido, o presente artigo está estruturado em dois eixos centrais: (1) reflexão teórica sobre as bases doutrinárias dos planos diretores tradicionais e, dessa forma aclarar as diferenças entre os tradicionais e os atuais planos diretores municipais participativos; (2) análise de duas experiências concretas da aplicação do Estatuto da Cidade quanto ao planejamento e à gestão urbanos democráticos, desdobrados em dois tópicos: (i) elaboração do Plano Diretor Participativo do município de Londrina/PR; (ii) análise da aplicação do orçamento participativo o município de Porto Alegre/ RS.

\section{DOS PLANOS DIRETORES TRADICIONAIS AOS PLANOS DIRETORES PARTICIPATIVOS}

"Com más razón debemos pensar en una ciudad construida en colaboración y en solidaridad, desde el diálogo y la participación" (CAPEL, 2010, p.26) 
Ao se pensar o plano diretor tradicional, é necessário observar a força desse instrumento para a atuação do Estado na produção e reprodução do espaço urbano, uma vez que o poder de interferência poderia atingir todos os setores que configuram o espaço das cidades.

No Brasil, a presença desse instrumento reporta-se ao Período Colonial, no qual a Coroa Portuguesa tinha a preocupação com o controle sobre as questões urbanísticas. Essas questões vinculavam-se, principalmente, ao padrão de organização espacial e sua estética. O modelo de organização do espaço urbano pautava-se nos princípios geométricos (plano xadrez), e a atuação do poder municipal voltava-se para a conservação e limpeza de ruas e praças.

De forma geral, pode-se considerar que é no final do século XVII e início do XVIII que principia a preocupação com o abastecimento d'água, tendo em vista o aumento na concentração da população nos centros urbanos. Essa preocupação refletiu-se no desenvolvimento de obras públicas nas cidades brasileiras. Entretanto, é apenas na metade do século XIX e, particularmente nas décadas iniciais do século $\mathrm{XX}$, que se encetam estudos e a elaboração de projetos de planejamento visando ao saneamento básico, as vias e a expansão das cidades. Em síntese, nesse período, os planos diretores para as cidades no Brasil constituíam-se inicialmente em planos viários. Em um segundo momento (décadas de 1930/40), inseriu-se nos planos diretores a questão do saneamento, porém, com uma orientação para o abastecimento de água (NYGAARD, 2005).

A base teórica e metodológica, na qual se assentava as formulações de planejamento urbano desses planos, era o positivismo, dando um cunho "determinista espacial" para os problemas urbanos. Assim, o planejamento urbano ganhou uma configuração físico-territorial, pois se pautava na visão de que, ao resolver os problemas locais do espaço físico, via reorganização desse espaço, com a implantação de infraestrutura, as desigualdades socioeconômicas, também, estariam sendo resolvidas. Portanto, a problemática social era determinada pelos aspectos estruturais de infraestrutura do espaço urbano e não pelas condições socioeconômicas das diferentes classes sociais.
O processo de urbanização, acelerado no Brasil a partir da década de 1950, fomentou uma conjuntura urbana que levou à intensificação da interferência direta do poder governamental no espaço urbano, mediante planos mais abrangentes, o que propiciou a diversificação de instrumentos governamentais de intervenção no espaço.

A formulação de planos diretores, a partir do movimento de transformação socioespacial urbana, ganhou ímpeto, nos fins dos anos de 1970 e durante os anos de 1980. A essência desses planos diretores era técnica e tinha a perspectiva de controlar as mutações do espaço urbano, isto é, o plano idealizava o ordenamento físico-espacial que abrangia toda a área urbana e a totalidade do conjunto das atividades da população. Nessa visão, a reestruturação urbana deveria ser traçada nos princípios de uma ordem lógico-ideal norteada no pressuposto positivista-cientificista.

Cabe destacar que a base teórico-metodológica desses planos vinculava-se diretamente ao positivismo, sobretudo ao positivismo lógico. Essa base doutrinária ganhava visibilidade mediante a natureza racional do planejamento que submetia o espaço urbano a leis e teorias, uma vez que o conhecimento científico era considerado o verdadeiro conhecimento, e este era delegado ao "saber competente" dos especialistas.

Nessa perspectiva teórico-metodológica, a realidade concreta das desigualdades socioespaciais era reduzida a "anomalias do tecido urbano", e não vista como expressões objetivas dos conflitos sociais fruto da lógica do modo de produção capitalista, marcada pela contradição entre capital, trabalho e luta de classes.

A essência do positivismo lógico nos planos diretores, produzidos nesse período no País, condiz perfeitamente com os interesses do Governo autoritário, particularmente, com a neutralidade de que se revestia o discurso científico, já que os princípios neopositivistas de uma ciência neutra, assentada na lógica matemática, proporcionariam aos cientistas (planejadores, técnicos, arquitetos, geógrafos, entre outros) uma atuação desprovida da interferência de preconceitos e juízos de valor. Assim os problemas urbanos somente se tornariam foco de ação se fossem passíveis de serem mensurados. 
Percebe-se a estreita ligação entre a postura ideológica do centralismo autoritário e a visão do planejamento pautado na máxima objetividade científica cuja eficácia remetia à anulação da discussão política. Tal alicerce político-filosófico fomentou a natureza tradicional do plano diretor das cidades brasileiras, cujas críticas corroboraram suas principais características, a saber: pretensioso, despolitizado, determinístico, autoritário, desligado da realidade e ineficaz (NYGAARD, 2005).

Nessa linha, foi criado em 1964 o Serviço Federal de Habitação e Urbanismo - Serfhau, com o intuito de implantar uma política nacional de desenvolvimento urbano e, particularmente, instituir e sedimentar no País uma visão de planejamento urbano e regional nos preceitos técnico-científicos do positivismo lógico.

O Serfhau orientou, nacionalmente, ao longo da sua duração (1964-1974), a preparação de planos locais de planejamento, mediante cursos, seminários e treinamentos oferecidos aos profissionais da área, conseguindo que a elaboração dos planos locais fossem homogeneizadas, isto é, não levavam em consideração as especificidades dos municípios, como, por exemplo, a dimensão territorial, a localização geográfica, as condições socioeconômicas entre outras características.

O destaque na postura do Serfhau era a defesa de que a atividade de planejamento, no caso, a confecção de planos locais de atuação no espaço urbano, constituía-se em uma função exclusiva de técnicos e de especialistas qualificados. Tal fato alicerçou a formação da tecnocracia vinculada à "tecnoestrutura estatal" (IANNI, 1979) que proporcionava respaldo à ação dos estadistas.

Desse modo, o conhecimento da realidade socioespacial somente ganhava veracidade mediante os estudos realizados por técnicos a partir do aporte científico. Logo, a promessa à população era de bem-estar e melhor qualidade de vida que seria promovida pelas propostas de intervenção dos especialistas, ou seja, caberia à população ficar passiva perante o planejamento e a gestão das cidades.

Todavia, tal visão do planejamento deveria ser suplantada como aclara Charbonneau (2002, p.1) ao colocar que: "Il est courant de penser que les professionnels de l'urbain doivent faire comprendre à d'autres, et notamment au public, les projets qu'ils ont, en tant que propriétaires du savoir, légitimité à vouloir imposer. Cette position est d'un outre temps".

Portanto, é exatamente na perspectiva de que essa posição dos profissionais, dedicados ao planejamento urbano, não condiz com a conjuntura atual ao considerar que o caminho para a superação da natureza idealística e tecnicista do plano diretor tradicional encontra seu fermento na participação social efetiva no planejamento e na gestão do espaço urbano, uma vez que o modelo de planejamento e de gestão público do tradicional plano diretor redundava na insatisfação cidadã em face do papel desempenhado pelo poder político local.

Tal fato, conforme Fernández (2010, p.25), dá ensejo à questão da importância da participação cidadã na gestão pública o que permite "[...] falar de uma espécie de 'novo espírito' da participação, que em maior ou menor grau está provocando o desenvolvimento de novas iniciativas que têm como objetivo consolidar a participação popular no desenho das soluções administrativas".

Nesse contexto, pondera-se que a Constituição Nacional (1988), bem como o Estatuto da Cidade (Lei $10.257 / 2001)$, possibilitou uma perspectiva de concretização de planos diretores pautados na participação dos segmentos sociais que produzem o espaço, fundamentalmente, os atores sociais, por tradição, excluídos do processo de construção da política urbana.

Para apreender as potencialidades de participação popular presentes no Estatuto da Cidade, cabe trazer para análise o próprio Estatuto que está estruturado de forma geral em quatro partes: (1) diretrizes gerais do Estatuto, que são as metas a serem atendidas e que envolvem as esferas do poder público (municipal, estadual e federal); (2) Gestão Democrática nas Cidades, importante conquista dos movimentos populares; (3) Plano Diretor, realçando seu papel como instrumento básico da política de desenvolvimento e de expansão urbana; (4) instrumentos previstos para se alcançar o princípio de função social da propriedade.

Volta-se o foco da análise para a Gestão Democrática nas Cidades, pois ela envolve diretamente a construção de planos diretores participativos, ou seja, apresenta uma expectativa de implantar um planejamento participativo. O Estatuto da Cidade incorpora o 
pressuposto de uma gestão democrática ao introduzi-lo como diretriz da política urbana, estabelecida no inciso II do Art. $2^{\circ}$, bem como prevê, no Art. 43, os mecanismos para a sua aplicação, ao estabelecer que:

Art. $2^{\circ}$ A politica urbana tem por objetivo ordenar o pleno desenvolvimento das funções sociais da cidade e da propriedade urbana, mediante as seguintes diretrizes gerais:

II - gestão democrática por meio da participação da população e de associações representativas dos vários segmentos da comunidade na formulação, execução e acompanhamento de planos, programas e projetos de desenvolvimento urbano.

Art. 43. Para garantir a gestão democrática da cidade, deverão ser utilizados, entre outros, os seguintes instrumentos:

I - órgãos colegiados de política urbana, nos níveis nacional, estadual e municipal;

II - debates, audiências e consultas públicas;

III - conferências sobre assuntos de interesse urbano, nos niveis nacional, estadual e municipal;

$I V$ - iniciativa popular de projeto de lei e de planos, programas e projetos de desenvolvimento urbano;

$V$ - (VETADO). (Lei Federal $n^{\circ} 10.257$ de 10/07/2001).

As audiências e consultas públicas são mecanismos basilares para garantir a gestão democrática da cidade, porque avalizam o princípio constitucional do direito do cidadão à informação e à participação. Assim sendo, essas modalidades/estratégias de participação pública devem ser promovidas pelo poder público com ampla divulgação. Com base nesse preceito, no âmbito municipal, as audiências públicas são obrigatórias para aprovação dos instrumentos de planejamento e de gestão como, por exemplo, o Plano Diretor e o Orçamento Anual.

No caso da elaboração do Plano Diretor, para atingir o objetivo central de um planejamento participativo, é necessário criar as condições para a efetiva participação popular em todas as suas fases, isto é, da configuração do Plano Diretor ao controle popular na gestão do poder executivo e legislativo municipal. Esses mecanismos estão previstos no $\S 4^{\circ}$ do artigo 40 do Estatuto da Cidade.

A realização de audiências e consultas públicas tem como finalidade informar, esclarecer e fornecer dados e documentos sobre o projeto do plano, isto é, seu escopo central é transmitir as informações necessárias à população para que ela/os cidadãos/as pessoas possa/m se posicionar em relação à proposta de planejamento municipal. Nesse ponto, pode-se incluir a defesa de Charbonneau (2002) sobre "la pédagogie urbaine" que corresponde à necessidade de criar uma dinâmica coletiva na cidade, pautada na tentativa de eliminar a imposição técnica vinculada ao poder governamental e construir um conhecimento comum da cidade para atingir um projeto coletivo. Consequentemente:

[...] la pédagogie passe par des méthodes dont l'objectif est résolument de partager le savoir, de générer des réactions par des documents très lisibles, faciles à aborder par tous, par des débats éclairés, animes par des professionneles, par une maîtrise du temps qui permettra aux projets d'évoluer (CHARBONNEAU, 2002, p.1).

Assim, além desse caráter educativo, é por meio das audiências públicas que os cidadãos têm o direito de manifestar suas opiniões, apresentar propostas e assinalar soluções e alternativas, ou seja, possuem o direto e o dever de participar do processo de elaboração do Plano Diretor municipal.

$\mathrm{Na}$ perspectiva de criar fóruns nacionais de discussão sobre a construção de uma política urbana, pautada em um modelo participativo presente no Estatuto da Cidade e defendido pelo Ministério das Cidades (órgão do Poder Executivo Federal), foi realizada a I Conferência Nacional das Cidades (2003) que resultou na eleição e na composição do Conselho das cidades - ConCidade.

De acordo com Cymbalista (2006), as contribuições desse Conselho são fundamentais para a implantação de planos diretores participativos. Por exemplo, na Resolução 25 do ConCidade há uma série de diretrizes para a elaboração de um plano diretor 
efetivamente participativo, com o intuito de construir uma cidade mais democrática. Essas diretrizes orientam que na coordenação de elaboração do plano diretor também esteja presente a sociedade civil, pois defendem que a leitura da realidade local tem que ser fruto da discussão com a comunidade.

O segundo objeto foco dessa análise, os Orçamentos Participativos, que baliza a gestão orçamentária participativa, está previsto no Estatuto da Cidade nos seguintes artigos:

Art. $4^{\circ}$ Para os fins desta Lei, serão utilizados, entre outros instrumentos:

(....)

f) gestão orçamentária participativa;

Art. 44. "No âmbito municipal, a gestão orçamentária participativa de que trata a alínea $f$ do inciso III do art. 4" desta Lei incluirá a realização de debates, audiências e consultas públicas sobre as propostas do plano plurianual, da lei de diretrizes orçamentárias e do orçamento anual, como condição obrigatória para sua aprovação pela Câmara Municipal. (Lei Federal n ${ }^{\circ} 10.257$ de 10/07/2001).

A prerrogativa de uma gestão orçamentária participativa assenta-se no fundamento de o cidadão exercer o direito de fiscalizar as finanças públicas em especial, o direito à participação na elaboração e na execução do orçamento municipal, o que representa a possibilidade de a população participar nas definições das prioridades de investimentos para cada local do município. Segundo Souza (2000 p. 44):

Na sua essência, o orçamento participativo consiste em uma abertura do aparelho de Estado à possibilidade de a população (de um municipio ou mesmo de unidades territoriais administrativas supralocais) participar, diretamente, das decisões a respeito dos objetivos dos investimentos públicos.

Entrementes, apesar de constar em lei federal, a gestão orçamentária participativa apresenta um caráter diferenciado no território nacional, uma vez que cabe ao poder municipal decidir, mediante Lei Orgânica e outras leis municipais, as finanças públicas, as diretrizes do processo de participação popular como pré-condição para a aprovação do orçamento anual do respectivo município. Consequentemente, a gestão orçamentária participativa ganha a especificidade da forma de sua aplicação em cada município brasileiro que utiliza o instrumento do orçamento participativo.

Nesse contexto, nos tópicos seguintes, será realizada uma reflexão sobre as perspectivas de planejamento e de gestão urbano-participativas, tendo como base duas realidades, elegidas com vistas a apreender a materialização de experiências concretas e as suas possibilidades reais de superação de um planejamento e gestão tradicionais.

\section{PONDERAÇÕES SOBRE AS EXPERIÊNCIAS CONCRETAS: O PLANO DIRETOR PARTICI- PATIVO DE LONDRINA E O ORÇAMENTO PARTICIPATIVO DE PORTO ALEGRE}

\begin{abstract}
Mesmo quando respaldados por leis, planos e instrumentos são, em princípio, apenas 'recursos', virtualidades, promessas. Só serão 'riquezas' quando puderem ser implementados eficazmente e ter a sua implementação eficazmente monitorada". (SOUZA, 2006b, p.34)
\end{abstract}

\section{Plano Diretor Participativo de Londrina/PR}

O município de Londrina está localizado na porção norte do estado do Paraná, inserido na Região Sul do Brasil. Londrina contava, em 2010, com um total de 506.701 habitantes, sendo que $493.520(97,4 \%)$ residiam no espaço urbano e $13.181(2,6 \%)$ no meio rural (IBGE, 2010), fato que evidencia a concentração populacional no seu espaço urbano, onde, consequentemente, afloraram e afloram os problemas, fruto de uma urbanização acelerada e desorganizada, que se constituíram na marca do processo de urbanização no Brasil.

Nesse contexto, o plano diretor municipal tornou-se instrumento de planejamento urbano de extrema importância na busca de se pensar o futuro da cidade, pautado nas contradições socioespaciais do presente. 
No caso de Londrina, o Plano Diretor Municipal de 1998 foi revisto e atualizado em 2008, para atender ao disposto no inciso III do Art. 40 do Estatuto da Cidade que estabelece: "A Lei que instituir o plano diretor deverá ser revista, pelo menos, a cada dez anos" (Lei Federal no 10.257 de 10/07/2001).

Esta análise centrou-se no processo de elaboração do referido plano no que diz respeito à prerrogativa da participação popular, com base nos dados obtidos de estudos dos pesquisadores do IPPUL (Instituto de Pesquisa e Planejamento de Londrina) e de documentos produzidos pelo Instituto.

$\mathrm{O}$ desencadear do processo ocorreu em maio de 2006, com a realização da $1^{\text {a }}$ Audiência Pública do Plano Diretor Participativo do Município de Londrina - PDPML, com o objetivo de obter e debater propostas para nortear o planejamento municipal.

Com o intuito de preparar ou "sensibilizar" a população para a discussão, foram promovidos fóruns e encontros em todas as regiões em que se encontra dividido o espaço urbano do município (Regiões: norte, sul, leste, oeste e centro, as quais foram criadas pelo IPPUL), bem como nos distritos rurais. Ressalta-se uma iniciativa inovadora colocada em prática em Londrina, o Plano Participativo Jovem de Londrina que culminou com a $1^{\text {a }}$ Conferência do Plano Diretor Jovem Participativo.

Para atingir o objetivo da concretização de um planejamento participativo, foi realizada a leitura comunitária, utilizando-se dos seguintes canais de participação popular: apoio à mobilização e gestão social participativa; fóruns de participação popular; seminários temáticos; reuniões e oficinas com públicos dirigidos; audiências públicas de pactuação; pré-conferências do Plano Diretor; conferências municipais do Plano Diretor e estratégia de comunicação e publicidade (IPPUL, 2008).

A partir desses mecanismos, adotados pela equipe técnica do IPPUL para promover o envolvimento da população londrinense na elaboração do plano diretor, obtiveram-se os seguintes resultados relativos à participação: na $1^{\mathrm{a}}$ Audiência Pública compareceram 338 participantes; no Encontro de sensibilização, 415, no Curso de formação de multiplicadores, 40, nos Fóruns de participação popular, 266, nas Pré-conferências, 415 e, na $2^{\circ}$, estiveram presentes 85 participantes e na $1^{\text {a }}$ Conferência, 306, respectivamente (IPPUL, 2008, p.17).

No relatório, encontra-se a observação de que não foi possível obter o real número de participantes envolvidos no processo apenas com a soma deles, tendo em vista que muitas pessoas participaram de mais de um evento, pois estavam representando alguma região ou associação de moradores entre outras organizações sociais.

O Comitê Gestor dos trabalhos estimou a participação de 100 mil pessoas de forma direta e indireta, os participantes eram compostos de: representantes e associações de moradores, sindicatos, organizações não governamentais, entidades profissionais, empresários, instituições de ensino e moradores. Nas pré-conferências, em termos quantitativos, a população dos distritos rurais apresentou, proporcionalmente, ao total de habitantes, um percentual maior que o do distrito sede (espaço urbano), ou seja, houve a participação de 103 pessoas de um total de 18.257 habitantes, equivalendo a $0,56 \% \%$; já o número de participantes do distrito sede foi de 223 pessoas de um total de 428.808 habitantes, o que representou $0,05 \%$ do total da população urbana.

$\mathrm{Na} 1^{\mathrm{a}}$ Conferência, observou-se uma queda em relação ao número de participantes tanto nos distritos rurais como no distrito sede. No primeiro caso, o total de participante foi de 37 pessoas, o que significa $0,2 \%$ da população dos distritos. No segundo caso, participaram 71 pessoas, representando $0,017 \%$ dos habitantes.

$\mathrm{O}$ resultado dos debates e das discussões foi a apresentação de 459 propostas das regiões e dos setores, por eixos temáticos, destinadas a compor o plano diretor, o que "[...] se traduziu num diagnóstico da realidade municipal por unidades espaciais de planejamento (UEP), uma vez que as propostas foram formuladas com o objetivo de propor soluções para os problemas vivenciados pelas regiões [...]" (IPPUL, 2008 , p. 49, grifo dos autores). Pode-se considerar que a baixa participação da população nas conferências não significou um empecilho na elaboração de propostas para o planejamento do município.

Não obstante, a questão que se sobressai dos dados de participação é que grande parte da população não se encontra engajada na atuação coletiva em prol de um planejamento democrático, já que a elaboração 
do plano diretor, como instrumento do planejamento participativo, visa garantir o direito de a população participar do plano futuro da organização e reorganização da sua cidade.

Cabe destacar que os pressupostos contidos no Estatuto da Cidade para garantir a participação popular, em todas as fases do processo de elaboração (revisão) do plano diretor, foram colocados em prática pela equipe técnica do IPPUL, ou seja, o relatório da leitura comunitária demonstra a cristalização dos mecanismos e sistemas de informação, de consulta e de participação da população na fase de construção do plano diretor de Londrina que se pode designar de plano diretor participativo, apesar da não participação massiva da população.

Não se pode esquecer que a sociedade brasileira ainda se encontra envolta na visão imposta pelo governo autoritário e pelos tradicionais planos diretores que delegavam ao "discurso competente" o planejamento do espaço urbano. Destarte, o caminho para eliminar a força ideológica da passividade social em face dos problemas coletivos do espaço urbano é longo. Contudo, é necessário colocar em prática mecanismos que fomentem a participação popular, como, por exemplo, o plano diretor participativo. Nesse ponto, ressalva-se a iniciativa inovadora do Plano Diretor Jovem Participativo de Londrina que representa uma ação em direção a uma sociedade consciente e atuante em seu espaço.

Tendo em vista o limite do presente artigo, não será possível detalhar esta experiência com comunidade escolar de Londrina. Entretanto, é interessante citar o objetivo central que norteou a iniciativa que se constituiu em:

Introduzir no contexto pedagógico escolar a criação da cultura de planejamento e gestão participativa no município, incentivando a construção permanente de conhecimentos, decisões e propostas coletivas do conhecimento da realidade urbano-rural e ambiental local, propiciando o pleno exercício de cidadania (IPPUL, 2008, p. 138).

Da visão geral da elaboração do PDPML, destaca-se a potencialidade de o plano jovem parti- cipativo colaborar com a formação de pessoas mais críticas para "ler" o mundo e participar da sua transformação, uma vez que a prática da participação da população no planejamento urbano não pode se restringir na elaboração do plano diretor, mas caminhar junto na execução dele, isto é, a participação popular e controle social das políticas de desenvolvimento urbano requerem a conscientização da sociedade do seu poder de atuação junto à gestão municipal.

Assim, desse ponto de vista, a efetivação dos instrumentos democráticos de planejamento e gestão do território urbano está intrinsecamente atrelada à postura que a sociedade brasileira assumir perante a produção socioespacial. Por conseguinte, ressalta-se a importância do desenvolvimento de ações junto à população jovem do município, já que essa postura advém de uma formação voltada para a conscientização da necessidade do comprometimento da sociedade com o aprofundamento democrático.

No entanto, apesar de verificar-se uma participação anêmica dos cidadãos londrinenses na elaboração do plano diretor municipal, pondera-se que os procedimentos participativos colocados em prática exerceram uma função cidadã, pois os mecanismos de participação demonstraram como a sociedade pode se envolver no planejamento e na gestão urbanos.

Essa questão torna-se fundamental ao se pensar o potencial dos atuais planos diretores municipais, tendo em vista que a credibilidade do plano fundamenta-se no fato de ele ter sido elaborado de forma transparente, pautado em debates e discussões com a sociedade, na perspectiva de pensar e orientar as diretrizes futuras da produção socioespacial, assentadas nas propostas e necessidades presentes no dia a dia de quem vivencia as contradições e os conflitos que marcam o tecido urbano.

Portanto, "[...] a participação popular é imprescindível, não apenas por força do Estatuto da Cidade, mas por uma necessidade de conferir representatividade (e, portanto credibilidade) ao próprio plano" (SABOYA, 2006, p. 9).

Observa-se que o motor que move as mudanças a favor da concretização da potencialidade dos planos diretores é a energia que emana da participação social. Contudo tal participação não pode ficar subjugada às forças de poder que trabalham no sentido 
contrário, ao buscar constantemente cooptação da coletividade em prol dos seus interessantes.

Não há dúvida de que a credibilidade depositada no plano permitirá que as ações a serem tomadas se orientem pelas propostas presentes no plano e não pelos interesses imediatos de uma gestão. $\mathrm{O}$ fato de a gestão não coadunar com os objetivos e as diretrizes presentes no plano diretor é um dos obstáculos enfrentados na elaboração do planejamento urbano, pois, em geral, os atores sociais (políticos e técnicos) que decidem a intervenção no território possuem intuitos que não condizem com os da coletividade, logo, como defende Saboya:

Apenas um plano com alta credibilidade tem capacidade de fazer com que essas pessoas abram mão de alguns de seus valores em função dos valores que estão expressos no plano. É preciso que essas pessoas vejam o plano como algo legítimo, acertado e representativo para abrir mão das suas próprias idéias do que é melhor para a cidade (2006, p.10).

A experiência da elaboração de plano diretor participativo visa consolidar a leitura comunitária mediante informações sistematizadas na leitura técnica as quais têm de ser construídas em linguagem acessível à maioria da população, pois essas informações são importantes para orientar as discussões. Tendo em vista estabelecer uma compreensão geral do município e, principalmente, expressar de forma transparente os objetivos das ações futuras para se atingir o princípio básico de uma reforma urbana - o direito à cidade, uma vez que as cidades brasileiras, incluindo Londrina, são marcadas pela desigualdade socioeconômica, por conseguinte, pela segregação socioespacial.

Considera-se que, em Londrina, o primeiro passo, que é a elaboração do plano diretor participativo, já foi dado, todavia, para galgar sua efetivação como potencial de mudança, é necessário monitoramento e controle social da gestão nos quais se veiculam a credibilidade do plano diretor.

\section{Orçamento Participativo de Porto Alegre/RS}

O segundo objeto de estudo de experiência concreta da presente reflexão é a gestão orçamentária participativa que tem sido colocada em prática em diferentes municípios do Brasil. A primeira experiência data do final da década de 1970, em Lages (Santa Catarina), em pleno regime militar. Entretanto, a condição política do período não proporcionou o seu desenvolvimento.

Entre as experiências do orçamento participativo, ganhou visibilidade à do município de Porto Alegre, iniciada em 1989, pelo fato de ter criado raízes ao longo dos anos na sociedade da capital do estado do Rio Grande do Sul, localizado na Região Sul do Brasil.

Em 2010, o município de Porto Alegre contava com 1.409.351 habitantes (população estimada para 2012 de 1.416.714 habitantes, IBGE, 2010), com $100 \%$ de taxa de urbanização. Esse fato levou os críticos a acreditar que esse modelo de participação popular, o universo populacional municipal, induziria a gestão orçamentária ao fracasso. Todavia, os dados do número de participantes no orçamento participativo porto-alegrense contrariaram esta previsão, conforme se pode constatar na evolução do número de participantes, a saber: 628 (1990), 3.086 (1991), 6.168 (1992), 6.975 (1993), 8.011 (1994), 8.495 (1995), 7.653 (1996), 11.078 (1997), 11.790 (1998), 14.776 (1999), 14.377 (2000) e 16.612 (2001), 17.241 (2002), 14.985 (2003), 13.337 (2004), 14.372 (2005), 11.536 (2006) (FEDOZZI, 2007, p. 23). O dado do orçamento participativo de 2012 revela o aumento de $11 \%$ na participação em relação a 2011, com um total de 16.721 pessoas credenciadas (OBSERVAPOA, 2012).

Os dados elucidaram a dinâmica consistente desse instrumento de gestão urbana e o avanço na agregação de participantes no orçamento público. Esse progresso participativo ganhou uma dimensão maior ao se levar em consideração não somente as pessoas que participaram das grandes assembleias, mas as que participaram de reuniões intermediárias, chegando cerca de $15 \%$ da população municipal (SOUZA, 2006).

A potencialidade do orçamento participativo expressa-se na forma inovadora de elaborar e executar 
o orçamento municipal e, principalmente, de introduzir o elemento essencial à participação, pois, mediante esse instrumento, as decisões sobre a arrecadação e os gastos públicos não ficam a cargo apenas dos técnicos da burocracia estatal e do governo, o poder é redirecionado para a participação direta de pessoas, comunidades, associações de moradores, movimentos sociais e organizações da sociedade civil.

Outro dado que merece ser colocado é o percentual do orçamento que é destinado à decisão popular. Em Porto Alegre, nos anos de 1999 e 2000, cerca de $21 \%$ e $15 \%$ do total da despesa municipal passou pelo orçamento participativo, respectivamente (SOUZA, 2000, 2006).

Para compreender a concretização da gestão orçamentária participativa, é importante visualizar como ela está organizada no espaço municipal. Primeiramente, o espaço foi divido em dezesseis regiões, e os critérios para sua delimitação foram geográficos, sociais e de organização comunitária. Além da regionalização, foram estipuladas as instâncias temáticas como: (1) organização da cidade e desenvolvimento urbano; (2) circulação e transporte; (3) saúde e assistência social, educação, cultura e lazer; (4) desenvolvimento econômico; e (5) tributação.

Sobre a dimensão espacial, é importante explanar que a divisão do município em unidades espaciais (regiões) para a aplicação do instrumento não foi uma decisão de gabinete, mas sim " [...] possui uma história que revela a incorporação e sentimentos de pertencimento (identidade sócio-espacial) e de certas tradições de organização do próprio ativismo de bairro local" (SOUZA, 2006, p.458). Tal fato é fundamental na adesão dos atores sociais à proposta da gestão orçamentária participativa, pois os laços identitários promovem a união em prol de um objetivo coletivo.

A implementação do orçamento participativo ocorre anualmente mediante a realização de duas grandes rodadas de reuniões plenárias nas regiões e nas instâncias temáticas. A primeira tem o objetivo de prestar contas sobre o plano de investimentos aprovado no ano anterior, com a finalidade de esclarecer a população sobre as metas que foram cumpridas ou não e o que ainda esta em andamento; na segunda, os moradores de cada rua, de cada bairro e os participantes das instâncias temáticas debatem e apresentam pro- postas sobre as prioridades para aquele ano e elegem seus conselheiros para o orçamento participativo, com mandato de um ano.

Cabe salientar que entre as duas grandes rodadas são realizadas diversas reuniões para o levantamento das principais carências e necessidades da população para a subsequente definição da ordem de atuação e das obras prioritárias (para mais detalhes da execução do orçamento participativo ver: Banco Mundial, 2008; FEDOZZI, 2007).

O sistema de gestão do orçamento participativo é formado por esferas públicas não estatais que são o Fórum de Delegados Regionais e Temáticos e o Conselho do Orçamento Participativo. Este último é composto de delegados e conselheiros escolhidos nas regiões e instâncias temáticas (no total de 44 conselheiros titulares).

Nas instâncias temáticas, são realizadas várias reuniões com os órgãos governamentais para a elaboração do orçamento municipal e do plano de investimentos. Terminada a elaboração, o plano será avaliado pelo Conselho do Orçamento Participativo (COP). Em seguida, inicia-se o intenso processo de discussão e negociação entre os conselheiros, a comunidade e os órgãos governamentais. A partir dessas discussões compõe-se a peça orçamentária que será encaminhada pelo prefeito à Câmara, para análise e votação. Ressalta-se um ponto fundamental em relação ao poder de veto do prefeito na proposta orçamentária, isto é, "uma maioria de dois terços dos conselheiros pode derrubar um veto do prefeito" (SOUZA, 2006, p.456).

Da experiência do orçamento participativo em Porto Alegre, fica evidente o potencial dessa forma de gestão orçamentária que, pautada em discussões e debates com a população, fortalece a valorização social de criar espaço para que as vozes dos atores sociais ganhem ressonância na atuação do poder executivo e legislativo municipal, fomentem o exercício da cidadania, pois, como defende Souza (2000, p. 45) a gestão orçamentária participativa de Porto Alegre extrapola o aspecto econômico-social, tendo em vista “[...] a contribuição 'pedagógica' do orçamento participativo, vale dizer, sua contribuição para formação de uma consciência de direitos [...]. Aí se inclui, com destaque, a sua contribuição para enfraquecer o caráter patrimonialista do Estado no Brasil". 
Essa contribuição fica evidente em depoimentos colhidos pelo autor em pesquisa no município, o que torna relevante transcrever um deles:

\section{Desde que eu participo do orçamento me sinto mais cidadão. Interessante; é uma grande... Satisfação. Me sinto muito bem. Eé por isso que me disponho a investir no processo, nas reuniões... Participar. Até porque eu acho que, pelo menos, é um exemplo que a gente dá (Apud: SOUZA, 2006, p. 453).}

Esse depoimento faz jus à relevância que a gestão orçamentária adquire junto à população do município e, particularmente, demonstra o potencial desse instrumento para que se criem as possibilidades de participação de uma sociedade consciente e atuante na produção do seu espaço. Essa questão é crucial no que tange às perspectivas que o orçamento participativo lança na sociedade, pois, além de promover a participação direta da população na decisão das prioridades na implementação dos equipamentos urbanos no seu espaço, fomenta a conscientização de que todos produzem o espaço urbano, criando a corresponsabilidade com o território.

Tal fato pode ser observado no estudo realizado por Fedozzi (2007) sobre as razões que levam as pessoas a integrar o grupo responsável pela elaboração do orçamento participativo, já que o resultado da pesquisa demonstra que a visão dessas pessoas passa por um processo de mudança, conforme o tempo de atuação e permanência no orçamento participativo, isto é, aqueles cuja participação é 5 a 8 anos ou mais têm um sentimento vinculado aos valores comunitários e democráticos maior do que o daqueles com menor tempo de presença no OP, o que evidencia a importância da questão de identidade com o território em que vivem.

Também, é visível nos dados a importância que assume as demandas dos equipamentos urbanos, ou seja, a falta deles no território porto-alegrense, uma vez que essa razão ficou entre $39,8 \%$ a $50,36 \%$ das respostas dos entrevistados.

A concretização das demandas no território, por conseguinte, a percepção do cidadão de que a sua qualidade de vida melhora mediante sua participação no processo decisório da gestão orçamentária fomenta o sentimento de que essa participação é importante, o que pode se traduzir na consciência cidadã.

Neste estudo, ficou evidenciado que Fedozzi (2007, p.40), também se preocupou em apreender as expectativas futuras do OP, tendo em vista a mudança partidária ocorrida nas eleições de 2004. Nas palavras desse autor: "Em síntese, pode-se inferir, em geral, que a percepção do público do $\mathrm{OP}$ - no contexto inusitado que se iniciou em 2005 - é que ele representa uma conquista que ultrapassa eventuais gestões administrativas ou partidos políticos".

A visão da base social do OP é que essa prática de cogestão sobrepõe os discursos partidários, reforça o poder de conscientização alcançado pelos participantes do OP, o que reafirma a potencialidade "pedagógica" de práticas que envolvam a participação social. Entretanto, cabe salientar que a sua atuação direta no espaço urbano está na sua função redistributiva, pois "[...] se bem explorada, pode configurar-se como uma significativa redistribuição indireta de renda, mediante o redirecionamento e a 'inversão de prioridades' quanto aos investimentos públicos, deixando-os de privilegiar os espaços residenciais já privilegiados" (SOUZA, 2006b, p.250, grifo do autor).

Essa função tem de estar atrelada á preocupação de se reduzir as desigualdades na presença de equipamentos urbanos (técnicos e sociais) nas cidades, o que pode contribuir para amenizar a marcante segregação espacial, uma vez que atuará junto à população que sofre diretamente as sequelas de viver em espaços segregados. Conforme o estudo feito por Maquetti (2002, p. 12) tendo como foco a função redistributiva do OP de Porto Alegre, o autor chega à seguinte apreciação:

Existe uma associação negativa entre a renda da região e o volume de investimento per capita. Há uma associação positiva entre a percentagem de mães com primeiro grau incompleto, a percentagem de domicilios e núcleos irregulares e a percentagem de habitantes com menos de quinze anos com o montante de investimento per capita em cada região. Análise similar realizada com o número de obras realizadas ou em execução 
por habitante no período 1989-2000 e os indicadores de pobreza mostraram os mesmos resultados. Pode-se concluir que o OP funcionou como um poderoso instrumento de distribuição de renda, as regiões mais pobres receberam maior volume de investimentos por habitante.

Os pontos analisados sobre a prática do orçamento participativo porto-alegrense permitem considerar que as potencialidades desse instrumento de gestão orçamentária, particularmente a função redistributiva e a função político-pedagógica, ganham destaque ao longo do processo histórico da sua implementação. Claro que o mecanismo participativo apresenta problemas, entre eles, por exemplo, o salientado por Souza (2006b) em relação à qualificação insuficiente de vários delegados e conselheiros, o que pode induzi-los a assumir uma posição defendida pelos técnicos da Prefeitura, exatamente para superar essa deficiência, o autor defende a inserção de um "planejador independente" no processo participativo, uma vez que a ausência de qualificação por parte da população pode se tornar um poderoso discurso da incapacidade social para tomar decisões, o que remete ao "discurso competente" que se tornou a matiz dos planos diretores tradicionais.

No entanto, a experiência de participação popular no OP revela-se como potencial de mudança na perspectiva de criar raízes uma mentalidade cidadã que, segundo os estudos, encontra-se forte para superar interesses de gestões não só específicos como também partidários. Indubitavelmente, não se pode ter a ilusão de que, em uma sociedade heterônoma, é possível acreditar que se alcançou o patamar mais elevado da participação social no OP, pois, assim como os avanços são claros, as deficiências existentes, também. Nesse sentido, é necessária a constante autocrítica dos mecanismos participativos para não subjugar as conquistas ao discurso de que se atingiu a "cidade democrática", porquanto ela está distante do horizonte de grande parte da população brasileira.

\section{CONSIDERAÇÕES FINAIS}

Ao trabalhar com esses dois objetos de análise, ou seja, a experiência do Plano Diretor Participativo de Londrina e o Orçamento Participativo de Porto Alegre, percebem-se avanços e retrocessos em ambas as realidades que são marcadas por contradições, uma vez que, na primeira realidade, foram colocados em prática todos os mecanismos necessários para a elaboração de um planejamento participativo, mas não houve avanço em relação à materialização de uma participação na gestão financeira pública mediante o orçamento participativo.

Já na outra realidade (Porto Alegre) constatou-se a concretização de uma gestão orçamentária considerada a mais arrojada no País. Entretanto, o planejamento participativo não ganhou a mesma dinâmica ao dispor de um plano diretor que divergiu do pressuposto da participação popular. Destarte, é necessário que as duas realidades desenvolvam propostas para superar esse paradoxo e, assim, criar as condições necessárias para ampliar a atuação social na produção do espaço.

Com base na análise dos dois objetos de estudo, considera-se que a superação do plano diretor tradicional é um desafio árduo para o planejamento e a gestão urbanos o qual está pontuado de obstáculos que poderão ser removidos pela conscientização da sociedade sobre o valor da participação popular. Isso é claro na luta por uma participação deliberativa e não apenas representativa.

Essa questão se reveste de fundamental importância, uma vez que o objeto que centraliza a presente análise sobre as potencialidades do planejamento e da gestão urbanos, participativos atrela-se à participação social.

Ao se alicerçar nesse princípio, é interessante elucidar os argumentos que sustentam a defesa da participação, ressalta-se a justificativa de cunho pedagógico e a participação como um meio que se justifica pelo poder de atuar diretamente na luta para melhorar a qualidade de vida nas cidades, visando a uma melhor eficiência econômica e gerencial dos recursos públicos. Esses argumentos ganham forma ao se analisar as potencialidades do orçamento participativo porto-alegrense, o que não se pode verificar no caso do plano diretor participativo de Londrina, uma vez que o processo é recente e, como se afirmou, o instrumento não encerra em si a finalidade ou a justificativa da participação social, já que cabe o controle social da aplicação das propostas, objetivos 
que constam no plano diretor municipal.

A partir dessa preocupação, salienta-se e reforça-se o fundamental valor de se realizarem pesquisas voltadas para a análise da forma de elaboração e concretização de planos diretores participativos e da gestão orçamentária democrática para fomentar o debate sobre as reais potencialidades presentes na legislação e, principalmente, a sua legitimidade junto à sociedade, por conseguinte explorá-la em prol da sua aplicação, pois, apesar dos novos horizontes das políticas de planejamento, as desigualdades socioespaciais no Brasil não foram abaladas.

Nesse sentido, é importante perscrutar o papel desempenhado pelos instrumentos de planejamento e de gestão urbanos presentes, nos planos diretores, a partir das prerrogativas do Estatuto da Cidade, particularmente, os instrumentos de gestão orçamentária democrática e de instrumentos como, por exemplo, o Imposto Predial e Territorial Urbano (IPTU) progressivo no tempo que pode promover maior "justiça social" ao atacar a especulação imobiliária, bem como pode sustentar a aplicação concreta do princípio da "função social da propriedade".

Entretanto, é importante elucidar que a instituição de uma lei não é a segurança da real participação social, porém constitui-se em um mecanismo fundamental para criar as condições necessárias para o avanço em direção a uma sociedade participativa. Nesse ponto, pode-se inferir que o Estatuto da Cidade, ao introduzir como pressuposto da política de desenvolvimento urbano a necessidade e a obrigatoriedade de planos diretores municipais participativos e a gestão orçamentária democrática, criou as condições para se acreditar na concretização da expectativa de um planejamento participativo no País.

Cabe reafirmar que as potencialidades não se restringem aos instrumentos de planejamento e gestão urbanos, no caso desta análise do plano diretor municipal participativo e do orçamento participativo, mas na sua legitimidade junto à sociedade, mediante os mecanismos participativos que dão voz ativa aos atores sociais, isto é, atrela-se à dinâmica socioespacial. Pois, delegar aos instrumentos esta responsabilidade não se estará trilhando o caminho para ultrapassar a visão tecnicista, despolitizada dos planos diretores tradicionais.

\section{REFERÊNCIAS}

BANCO MUNDIAL. Para um orçamento participativo mais inclusivo e efetivo em Porto Alegre. Relatório $n^{\circ} 40144-B R$. Washington /EUA, 2008.

BRASIL. Constituição da República Federativa do Brasil. Rio de Janeiro: Gráfica Auriverde, 1988.

BUSTELO, E. S. Planejamento e política social: a dialética do possível. IN: BROMLEY, R; BUSTELO, E.S (Org.). Politica $x$ técnica no planejamento. SP: Brasiliense, 1982, p.132-153.

CAPEL, H. Urbanización generalizada, derecho a la ciudad y derecho para la ciudad. In: XI COLOQUIO INTERNACIONAL DE GEOCRÍTICA. Buenos Aires, $2-7$ de maio de 2010. Actas... Buenos Aires: Universidad de Buenos Aires, 2010, p. 1-34. Disponível em $<$ http:www.filo.uba $>$, acesso em 10 de agosto de 2010.

CARVALHO, S. N de. Condicionantes e possibilidades políticas do planejamento urbano. In: VITTE, C. de C. S.; KEINERT, T.M.M. (Org.). Qualidade de vida, planejamento e gestão urbana: discussões teórico-metodológicas. Rio de Janeiro: Bertrand Brasil, 2009, p.21-67.

CHARBONNEAU, Jean-Pierre. Dossier: À école de la ville. Revie l'Urbanisme, 2002. Disponível em: www. revieunbanisme.fr. Acesso em 01 de maio de 2010.

CYMBALISTA, R. A trajetória recente do planejamento territorial no Brasil: apostas e pontos a observar. Revista Paranaense de Desenvolvimento. Curitiba, $\mathrm{n}^{\circ}$ 111, p.29-45, jul.dez. 2006.

FEDOZZI, L. Observando o Orçamento participativo de Porto Alegre - análise histórica de dados: perfil social e associativo, avaliação e expectativas. Porto Alegre: Tomo, 2007.

FERNÁNDEZ, E.G. Novos instrumentos de participação: entre a participação e a deliberação. In: SILVA, E. M. da; CUNHA, E. S. M. (Org.). Experiências inter- 
nacionais de participação. SP:Cortez, 2010. (Coleção Pensando a Democracia participativa, v.2), p.19-40.

IANNI, O. Estado e planejamento econômico no Brasil (1930 - 1970). $3^{\text {a }}$ ed. RJ: Civilização Brasileira, 1979.

IBGE - Instituto Brasileiro de Geografia e Estatística. Censos Demográficos (1970, 1991, 2000). Disponível em <www.ibge.gov.br>, acesso em 10 de abril de 2012.

IPPUL - Instituto de Pesquisa e Planejamento de Londrina. Plano Diretor Participativo de Londrina. Relatório de Leitura Comunitária. Londrina: IPPUL, 2008.

LEI FEDERAL n ${ }^{\circ} 10.257$ de 10/07/2001. O Estatuto da Cidade. Diário Oficial da União, Seção I (Atos do Poder legislativo). Edição n ${ }^{\circ} 133$ de 11 /07/2001.

LEFEBVRE, H. O direito à cidade. SP: Mores, 1991.

MARQUETTI, A. O orçamento participativo como uma política redistributiva em Porto Alegre. In: I ENCONTRO DE ECONOMIA GAÚCHA. Porto Alegre, 16-17 maio/2002. Disponível em: <www.fee.tche. br/sitefee/download/eeg/1/mesa_9_marquetti.pdf $>$, acesso em 20 de novembro de 2012.

NYGAARD, P. D. Planos Diretores de cidades. Discutindo sua base doutrinária. Porto Alegre: Editora da UFRGS, 2005.

OBSERVAPOA (Observatório da cidade de Porto Alegre). Orçamento Participativo. Disponível em: $<$ www2.portoalegre.rs.gov.br/observatório>, acesso em 30 de novembro de 2012.

RODRIGUES, A. M. Direito à cidade e o Estatuto da Cidade. Cidades. Presidente Prudente, v.2, $\mathrm{n}^{\mathrm{o}} .3$, p.89-110, 2005.

SABOYA, Renato T. de. Planos diretores como instrumento de orientação das ações de desenvolvimento urbano. Arquitextos. São Paulo: Vitruvius, jul de
2006. Disponível em: <http://www.vitruvius.com.br/ revistas/read/arquitextos/07.074/338>, acesso em 30 de novembro de 2012.

SOUZA, M.L de. Os orçamentos participativos e sua espacialidade: uma agenda de pesquisa. Terra Livre. São Paulo, no 15, p.39-58, 2000.

- Mudar a cidade: uma introdução crítica ao planejamento e à gestão urbanos. $4^{\mathrm{a}} \mathrm{ed}$., RJ: Bertrand Brasil, 2006a.

. A prisão e a ágora. Reflexões em torno da democratização do planejamento e da gestão das cidades. Rio de Janeiro: Bertrand Brasil, 2006b.

SOUZA, M. L de; RODRIGUES, G. B. Planejamento urbano e ativismos sociais. São Paulo: UNESP, 2004.

Soc. \& Nat., Uberlândia, 25 (2): 239-254, mai/ago/2013 